\title{
Influence of Road Wetness on Tire-Pavement Rolling
}

\section{Resistance}

\author{
Jerzy Ejsmont ${ }^{1}$, Leif Sjögren ${ }^{2}$, Beata Świeczko-Żurek ${ }^{1}$ and Grzegorz Ronowski ${ }^{1}$ \\ 1. Technical University of Gdańsk (TUG), Mechanical Faculty, Gdańsk 80 233, Poland \\ 2. Swedish National Road and Transport Research Institute (VTI), Linköping 581 95, Sweden
}

\begin{abstract}
Rolling resistance of tires is one of the most important factors influencing energy consumption of road vehicles, especially on rural roads. For practical reasons, most of rolling resistance measurements are usually performed for dry road conditions. Based on the fact that roads are wet during a considerable time over the year and as part of the projects MIRIAM, ROLRES and ROSANNE, the TUG (Technical University of Gdańsk) in Poland and VTI (Swedish National Road and Transport Research Institute) in Sweden carried out trailer rolling resistance measurements on wet road surfaces to investigate water film influence on rolling resistance on different pavements. A specially-designed trailer to measure rolling resistance has been used. The test sections were both rural roads and an abandoned airfield equipped with water film sensors mounted in the pavement. Results indicate strong influence of test speed and water film depth, as well as influence of surface texture. The increase of rolling resistance on wet surfaces is caused by both hydrodynamic phenomena and cooling effect of water that decreases tire temperature thus increasing rolling resistance.
\end{abstract}

Key words: Tires, rolling resistance, road wetness, water film.

\section{Introduction}

Rolling resistance is one of the most important functional properties of road pavements. It is applicable to the entire road network. Rolling resistance affects the energy consumption and emissions from vehicles. As rolling resistance is caused by an interaction between the tire and road, it is necessary to consider both factors.

A water film covering the road surface influences many important characteristics of the tire/pavement interaction, most notably friction, tire/road noise and rolling resistance. Many parameters affect the road wetness and the total time of it being wet enough to affect rolling resistance. Weather/climate, road construction including maintenance strategies and resulting road condition and the type and amount of traffic are the major sources affecting the degree and time of wetness. The most important meteorological

Corresponding author: Jerzy Ejsmont, professor, research fields: tire rolling resistance, tire/road noise and military vehicles. E-mail: jejsmont@pg.gda.pl. parameter is precipitation. Considering road construction, the drainage performance and the pavement design (material and structure) are the most important factors. But even more important here is probably the condition of the road construction, such as the degree of rutting and crossfall, as well as the function of the drainage system.

Besides the drainage system, evaporating, splashing and heating from traffic are factors in the drying process. All those make it difficult to give numbers on how long a road is being affected by significant wetness. By looking on meteorological data from the SMHI (Swedish Meteorological and Hydrological Institute), we can establish the number of days (in 2013 ) with precipitation to around 180 and dry days to around 148 , counting up to at least $49 \%$ wet and $41 \%$ dry days in Sweden (37 days were unclassified). Statistics show the following relative frequency of various types of precipitation over the course of a typical year: drizzle: $4 \%$; light rain: $40 \%$; moderate rain: $21 \%$; light snow: $14 \%$; moderate snow: $18 \%$; heavy snow: $1 \%$; thunderstorms: $3 \%$. In Gdańsk, 
Poland, typically $45 \%$ days are with some kind of precipitation. It must be observed that precipitation may be very short and road wetness may diminish quickly, so daily data presented above should be considered only as a general trend. Anyway, there is no doubt that, in central and northern Europe, the roads are wet for a considerable time during a year. Of course, it is during the winter time that the surfaces are more continuously wet, almost the whole day and night. In the summertime, it is more complicated with a complex integration of rain intensity, time of the day, if the section is in the shadow, the pavement construction, road condition, uphill or downhill, traffic intensity and type of traffic. Anyway, this implies that wet road conditions must be considered in calculations on traffic effects analyzing rolling resistance. This is confirmed by Karlsson et al. [1] that also concludes that "the road surface is wet for a significant time during a typical year".

\section{Test Method, Tires and Road Sections}

Based on the fact that roads are wet during a considerable time over the year and as part of the international project MIRIAM [2], an investigation has been done on the water film influence on tire rolling resistance. The equipment, test sections and the used method are described in more detail in the following sections.

\subsection{Test Method and Measuring Equipment}

Tire rolling resistance is very difficult to measure in real road conditions. Measurements are subjected to many disturbances that may spoil the results [3, 4]. Generally, rolling resistance force is only at about $1 \%$ of tire load. This means that, in order to withstand considerable tire load (in the case of passenger car tires in order of $4,000 \sim 6,000 \mathrm{~N}$ ), the measuring system must be rather strong and heavy but at the same time must be able to measure rolling resistance with acceptable precision in the order of a resolution of $0.5 \mathrm{~N}$ or less. All this has to be accomplished in a rather harsh environment with possible disturbing forces due to acceleration/deceleration, road grade, temperature changes, etc.

There are only a few test devices in the world that are capable of doing efficient and precise measurements of rolling resistance on the road, TUG's test trailer $\mathrm{R}^{2}$ Mk.2 being one of them. Test trailer $\mathrm{R}^{2} \mathrm{Mk} .2$ is shown in Figs. 1 and 2 where details of the measuring system are visible. The complete system and principles of the trailer construction are described in Refs. [5, 6]. The test wheel is mounted on a vertical arm, and the rolling resistance force acting on the wheel swings the arm backwards. The rate of swing is measured by a laser sensor system, while the tilt of the complete trailer relative road is monitored by separate laser sensors measuring the distance of the front and rear part of the trailer to the road surface. The trailer is equipped with patented system compensating influences of acceleration/deceleration and road grade. Temperatures of tire sidewall and road surface are monitored by noncontact infrared temperature sensors. Air temperature outside the protective chamber is also measured and recorded. It must be observed that thermal conditions of the tire mounted in the trailer may differ from conditions that would be typical for passenger cars, as the tire is enclosed in protective chamber. The chamber is necessary to eliminate air flow around the tire that creates air drag influencing measurements. Specially-designed precise altimeter system monitors grade of the road.

\subsection{Test Tires}

At present there is no international standard specifying rolling resistance measurements on the road, thus there are no nominated reference tires. As test tires, four tires described in Table 1 were used.

Tire set included two tires specified as reference tires in the future ISO 11819-3 standard for tire/road noise measurements [7] (designated as SRTTD and AAV4D), one of that is considered by TUG as an 
Table 1 Test tires.

\begin{tabular}{lllll}
\hline Designation & Manufacturer & Model & Size & Remarks \\
\hline AAV4D & AVON & AV4 & 195R14C & $\begin{array}{l}\text { Mud and snow tire that is also a reference tire } \\
\text { according to ISO/TS 11819-3 }\end{array}$ \\
\hline SRTTD & UNIROYAL & Tiger Paw & P225/60R16 & SRTT (standard reference test tire) \\
\hline MCPRD & MICHELIN & Primacy HP & 225/60R16 & High quality market tire \\
\hline VTICD & PIRELLI & P1 Verde & 195/60R15 & Market tire for medium size passenger cars \\
\hline
\end{tabular}

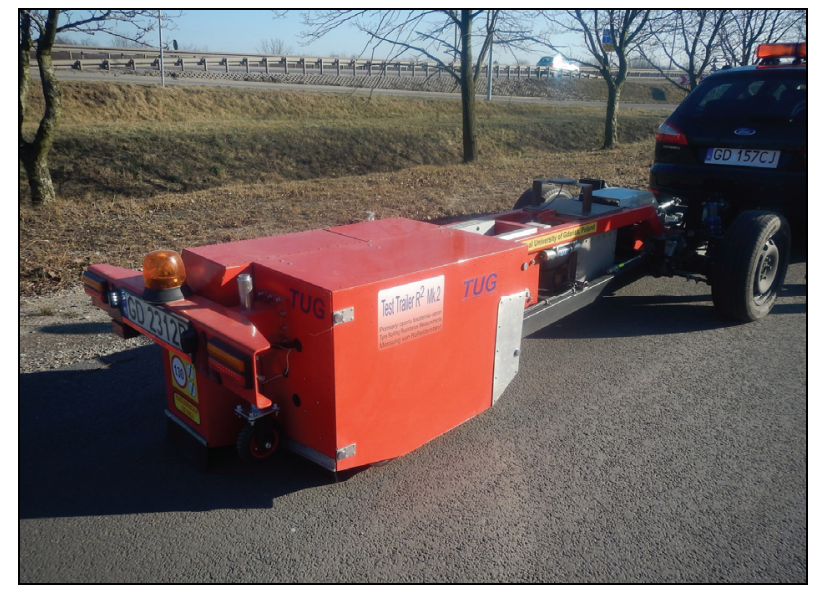

Fig. 1 Test trailer $\mathbf{R}^{2}$ Mk.2.

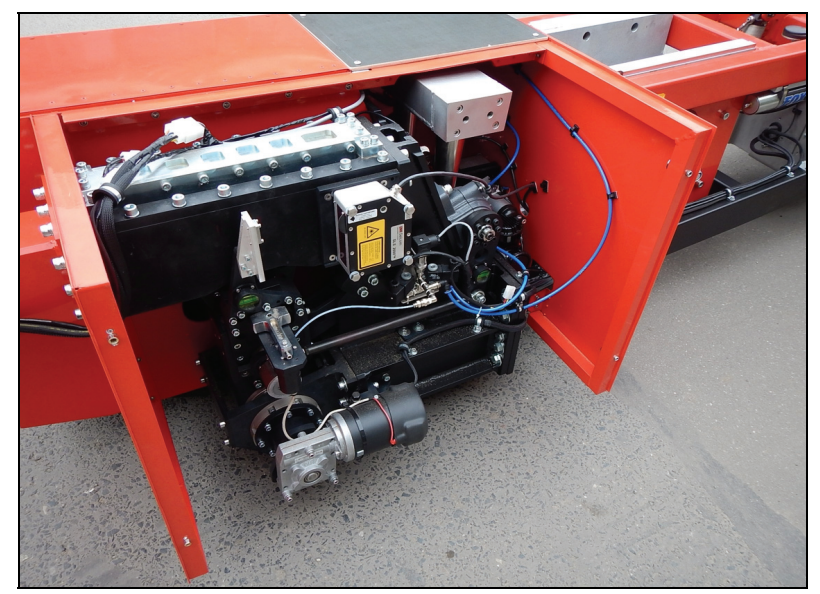

Fig. 2 Measuring system of $\mathbf{R}^{2}$ Mk.2 trailer.

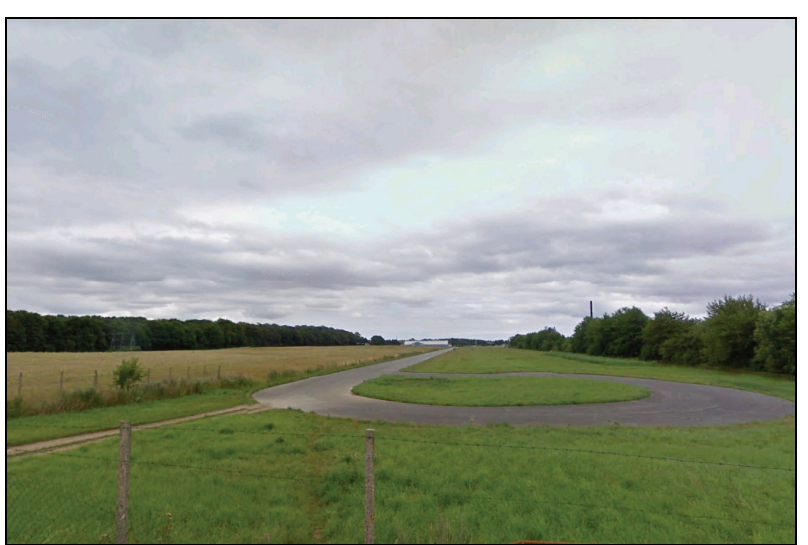

Fig. 3 Test section in Horsens. informal reference tire for rolling resistance measurements-Michelin Primacy HP 225/60R16 (designated as MCPRD) and a fourth tire from Pirelli (designated as VTICD). They have been selected as representing a spectra of modern passenger car tires in Europe.

Inflation pressure for tires AAV4D, MCPRD and SRTTD was regulated to $210 \mathrm{kPa}$, and for tire VTICD, it was capped at the value of $240 \mathrm{kPa}$. The tire load was set to be $4,000 \mathrm{~N}$.

\subsection{Test Sections}

In October 2013, TUG together with VTI performed tests of water film influence on rolling resistance on a runway at the Horsens abandoned small airfield in Denmark (Fig. 3). The facility in Horsens is equipped with water film sensors mounted in the pavement. There is also a weather station that continuously records weather conditions and water film thickness over each sensor (Fig. 4).

The test road in Horsens was paved with dense asphalt concrete based on aggregate $11 \mathrm{~mm}$. In this article, the Horsens pavement is defined as DAC11. Texture measurements performed on this section revealed that MPD (mean profile depths) was in range of $0.38 \sim 0.56 \mathrm{~mm}$ with an average of $0.44 \mathrm{~mm}$.

Before the measurements, it was planned to test all tires on the dry pavement and, after that, begin to wet the surface using a water-truck and to adjust the water film by more or less frequent passes of this truck. Unfortunately, at the day of measurements, the weather was rainy, and in the evening, the hurricane "Christian" reached Denmark. Due to this weather, it was not possible to test the tires in $100 \%$ dry conditions. On the other hand, it was possible to test 


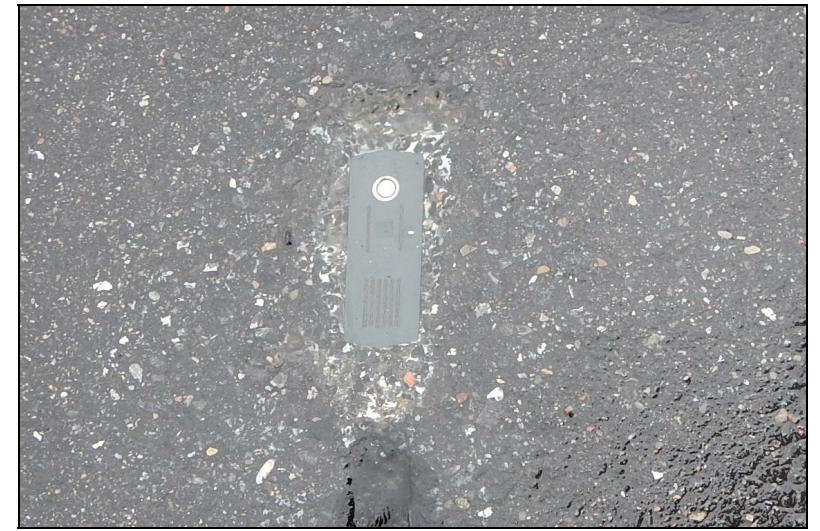

Fig. 4 Water film sensor on the test track in Horsens.

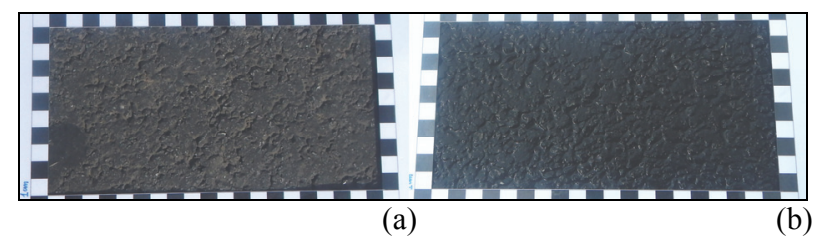

Fig. 5 SMA8 surface: (a) dry; (b) wet.

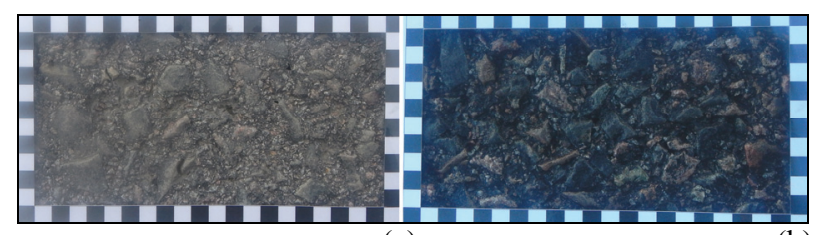

(a)

(b)

Fig. 6 Pavement at the test site Rokinge: (a) dry conditions; (b) wet conditions.

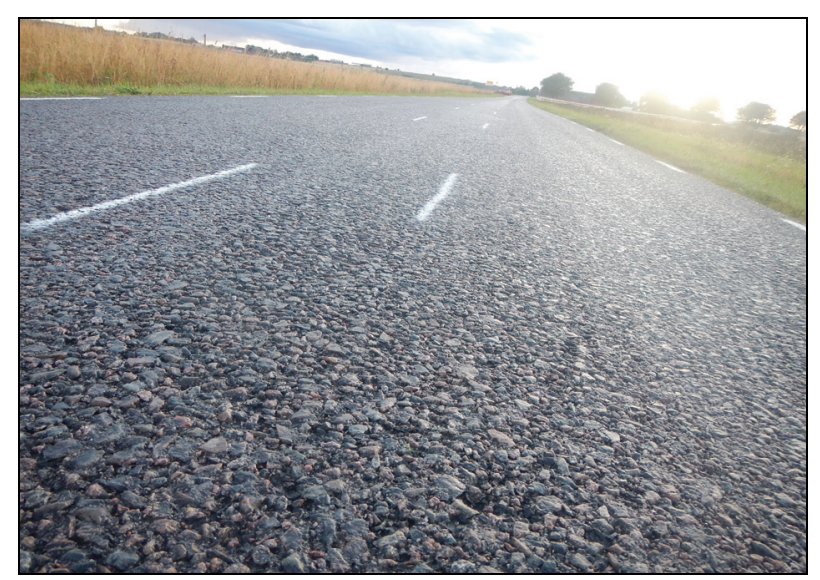

Fig. 7 View on test site in Rokinge (wet conditions).

tires on considerably thick water film that was provided by both the rainfall and water-truck. The driest conditions that were tested on that day may be described as "damp", meaning that the road surface was "black" but with no visible and shiny water film on it. The sensors indicated a water film of $0.08 \mathrm{~mm}$ during these "damp" conditions.

In order to complete the results with missing dry values of rolling resistance coefficients, the data were supplemented with results obtained on a similar surface and at a similar air temperature elsewhere. Those measurements were performed with nominally the same tires coming from the same batch.

Routine measurements that are performed within different projects from time to time are interrupted by periods of rain. A typical procedure in the case of rainfall is to stop measurements and wait until tested pavements are dry. In order to obtain more data about influence of pavement wetness on rolling resistance, in a few cases, the measurements were carried out despite pavement wetness. Unfortunately, in such a case, there is no chance to measure thickness of water film, so only qualitative description of the "wetness" is possible.

During summer of 2014, three tires were tested on special SMA (stone mastic asphalt) with 8-mm aggregate $(\mathrm{MPD}=1.5 \mathrm{~mm})$ designated here as SMA8, at speed $50 \mathrm{~km} / \mathrm{h}$ in dry and wet conditions. In this case, wet surface means light to moderate rain. Pictures of the surface are presented in Fig. 5.

During measurements performed in 2014 on a test section close to Rokinge in Sweden, the measurements were also interrupted by rain. On the next day, it was, however, possible to perform measurements on a dry surface, so the obtained data may be used for wetness influence evaluation. The pavement at Rokinge test site was rather unique, as it was a kind of a very coarse surface dressing with 25-mm aggregate (Figs. 6 and 7). MPD for this surface was $1.9 \mathrm{~mm}$. This pavement is designated as $\mathrm{SD} 25$ in the article.

\section{Results of Measurements}

The results obtained for tire SRTTD at speeds of $30 \mathrm{~km} / \mathrm{h}, 50 \mathrm{~km} / \mathrm{h}$ and $80 \mathrm{~km} / \mathrm{h}$ in Horsenes on test section DAC11 are presented in Figs. 8-10. For all speeds, clear increase of rolling resistance is observed. 
At speed of $30 \mathrm{~km} / \mathrm{h}$, the increase of rolling resistance coefficient $C_{r}$ is well correlated with the water film thickness. For $0.8-\mathrm{mm}$ thick water film, the value of $C_{r}$ is at about $30 \%$, higher than for dry conditions. At higher speeds, the increase of $C_{r}$ due to water film is more rapid, and the increase of $40 \%$ is reached already for water film thickness of $0.3 \mathrm{~mm}$. For thicker water films, the rolling resistance coefficient stabilizes. It must be mentioned, however, that water film thickness of $0.8 \mathrm{~mm}$, even at speed of $80 \mathrm{~km} / \mathrm{h}$, was not enough to cause aquaplaning.

In Figs. 11-13, corresponding results obtained for tire AAV4D are presented. Although magnitude of rolling resistance increase at speed of $30 \mathrm{~km} / \mathrm{h}$ is similar with the one for tire SRTTD at higher speeds; The increase of rolling resistance is higher and more

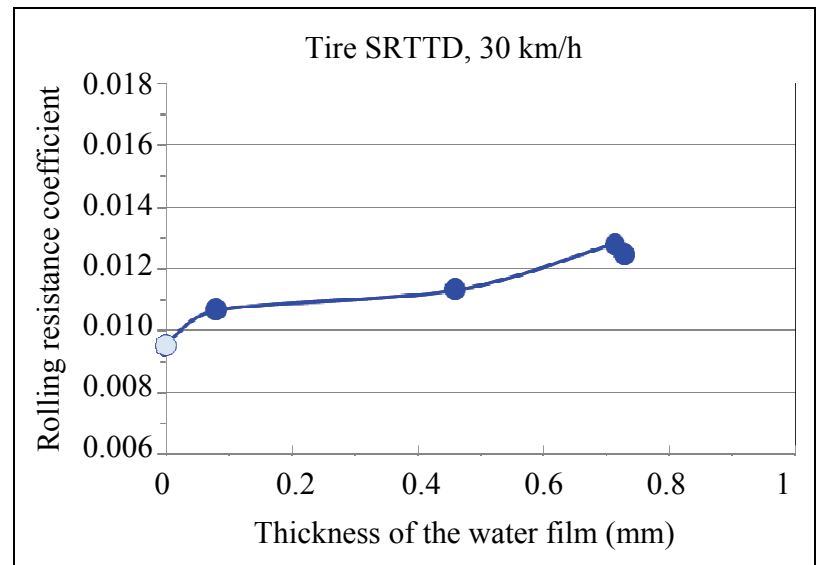

Fig. 8 Influence of water film thickness on pavement DAC11 for tire SRTTD at speed of $30 \mathrm{~km} / \mathrm{h}$.

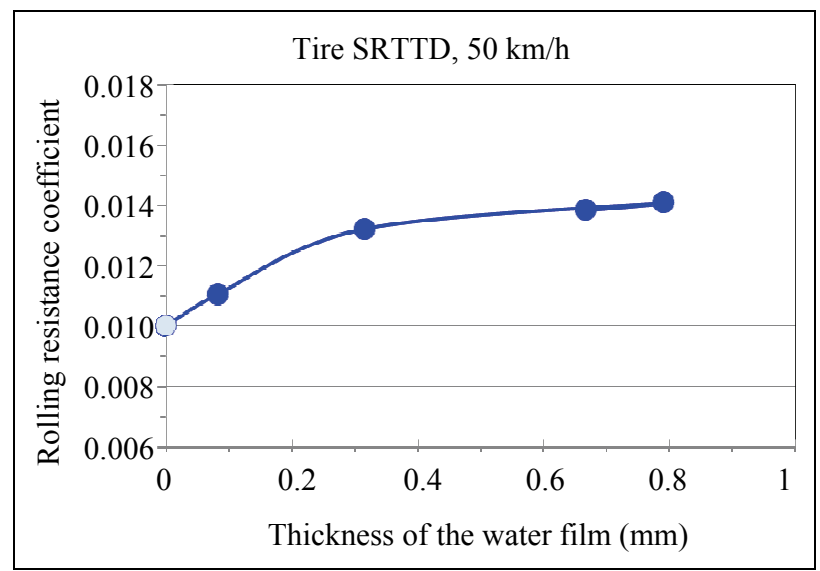

Fig. 9 Influence of water film thickness on pavement DAC11 for tire SRTTD at speed of $50 \mathrm{~km} / \mathrm{h}$. related to water film thickness. At $80 \mathrm{~km} / \mathrm{h}, 0.65-\mathrm{mm}$ thick water film increases rolling resistance by over $50 \%$, and most probably, it would increase even more for thicker water films as it indicates possible extrapolation of the curve.

Measurements performed on SMA8 road surface were supplemented by measurements of tire and pavement temperatures, as it is obvious that precipitation influences their thermal conditions. What is more, tire rolling resistance is strongly dependent on tire temperature. In average, tire rolling resistance increases by $1 \%$ for temperature decrease of one centigrade. This leads to the conclusion that water film on the road restricts tire movement not only by mechanical and hydraulic means but also due to the cooling effect on the tire structure.

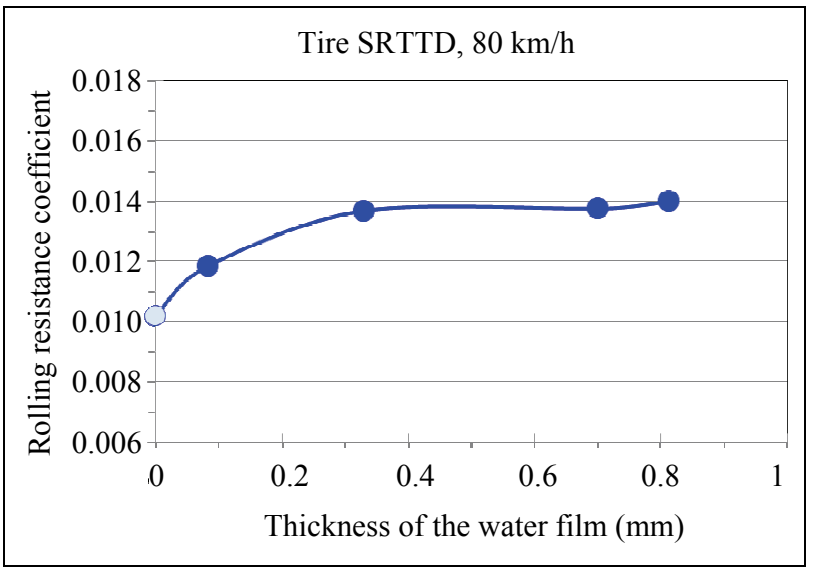

Fig. 10 Influence of water film thickness on pavement DAC11 for tire SRTTD at speed of $80 \mathrm{~km} / \mathrm{h}$.

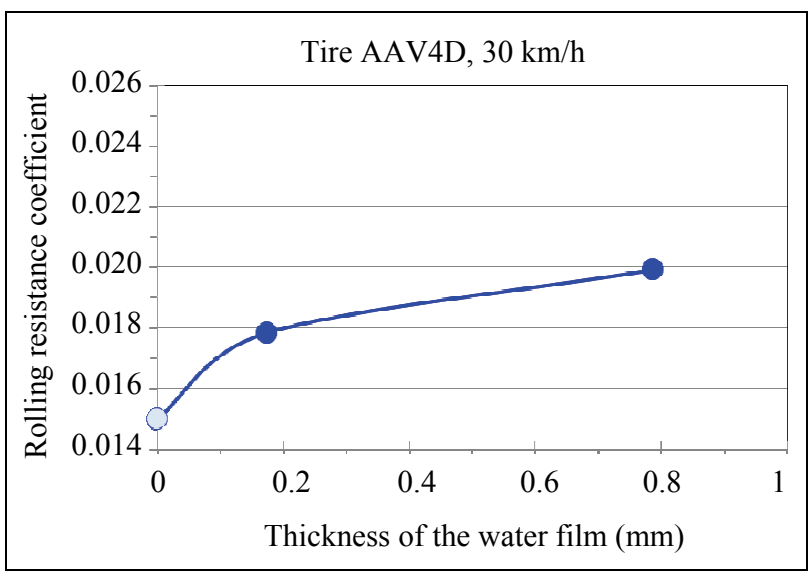

Fig. 11 Influence of water film thickness on pavement DAC11 for tire AAV4D at speed of $30 \mathrm{~km} / \mathrm{h}$. 


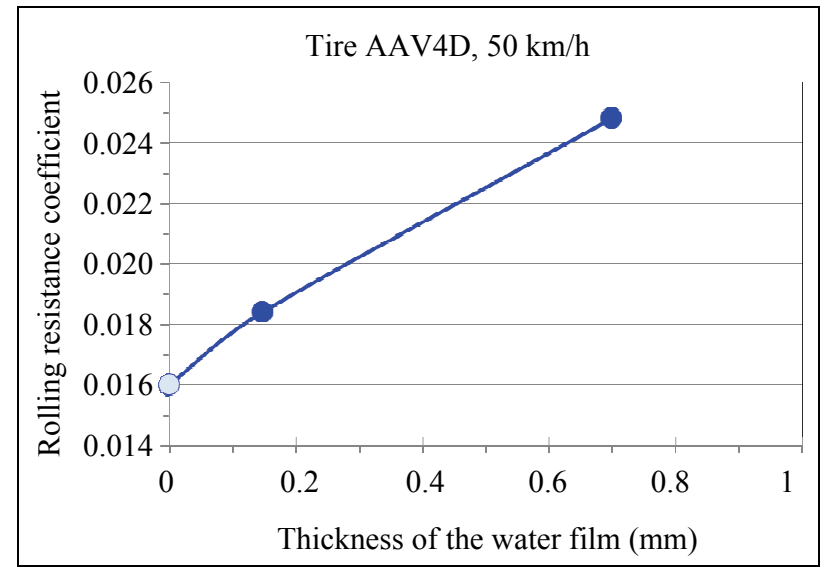

Fig. 12 Influence of water film thickness on pavement DAC11 for tire AAV4D at speed of $50 \mathrm{~km} / \mathrm{h}$.

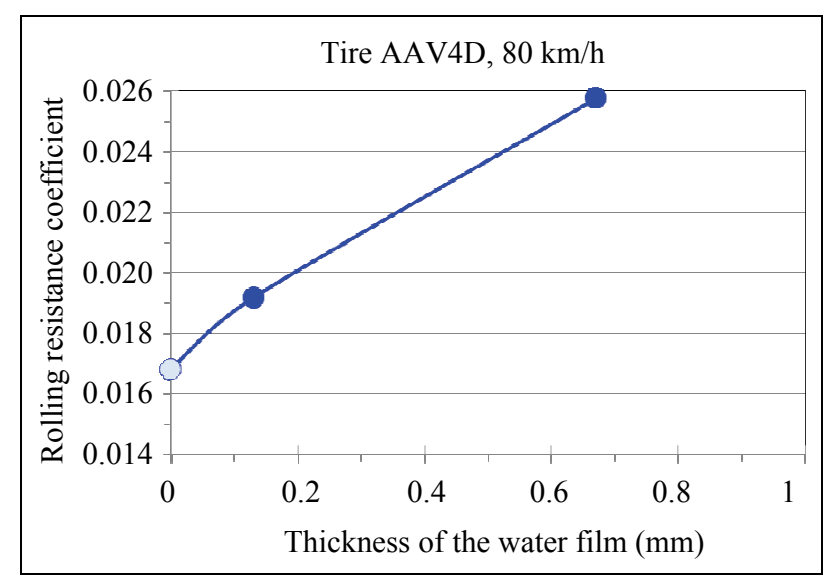

Fig. 13 Influence of water film thickness on pavement DAC11 for tire AAV4D at speed of $80 \mathrm{~km} / \mathrm{h}$.

In Figs. 14-16, results of measurements performed on the SMA8 pavement are presented. For each tire, wet surface increases rolling resistance and decreases temperature of the sidewalls. The biggest increase of rolling resistance was observed for tire MCPRD and it was as high as $40 \%$. It is necessary to notice that tire MCPRD was tested during more intensive rainfall than other tires. For other tires, the increase of rolling resistance was close to $10 \%$. For all tires, temperature of the sidewalls decreased by $6 \sim 8{ }^{\circ} \mathrm{C}$ due to rain (those values account for differences in air temperature between dry and wet measurements).

It is commonly accepted that temperature influence on rolling resistance is well described by Eq. (1):

$$
C_{r_{t_{1}}}=C_{r_{t_{0}}}\left[1+K_{t}\left(t_{0}-t_{1}\right)\right]
$$

where:

$C_{r_{t_{1}}}$ : coefficient of rolling resistance at temperature $t_{1}$

$C_{r_{10}}$ : coefficient of rolling resistance at temperature $t_{0}$

$K_{t}$ : temperature influence coefficient.

TUG has established values of $K_{t}$ for several tires [5]: For tire AAV4D, $K_{t}=0.010$; For tire SRTTD, $K_{t}=0.015$; For tire MCPRD, $K_{t}=0.012$. Although Eq. (1) was introduced to account for air temperature differences, it may also be used for calculations based on tire sidewall temperatures. Assuming that cooling effect due to the road wetness leads to the decrease of tire temperature by $7{ }^{\circ} \mathrm{C}$, for tire AAV4D, the corresponding increase of rolling resistance would be $7 \%$, for tire SRTTD $10.5 \%$ and for tire MCPRD 8.5\%.

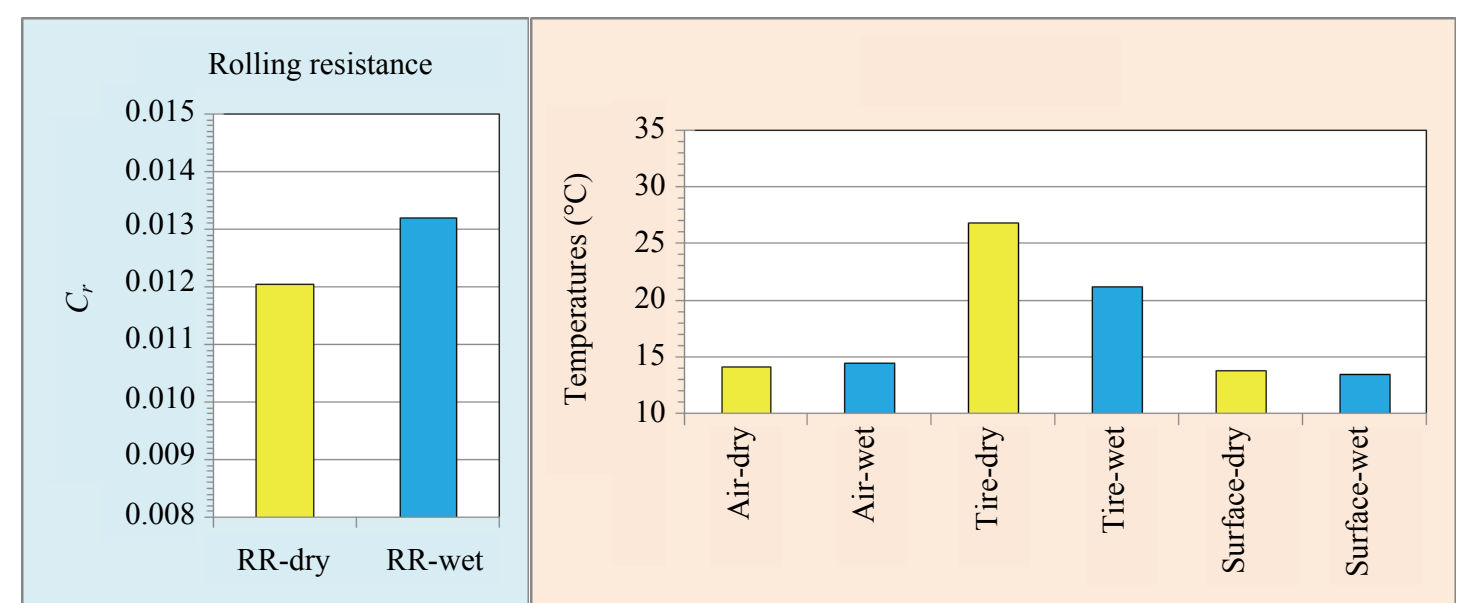

Fig. 14 Influence of wetness on coefficient of rolling resistance and temperatures during measurements for tire AAV4D on SMA8 pavement at speed of $50 \mathrm{~km} / \mathrm{h}$. 


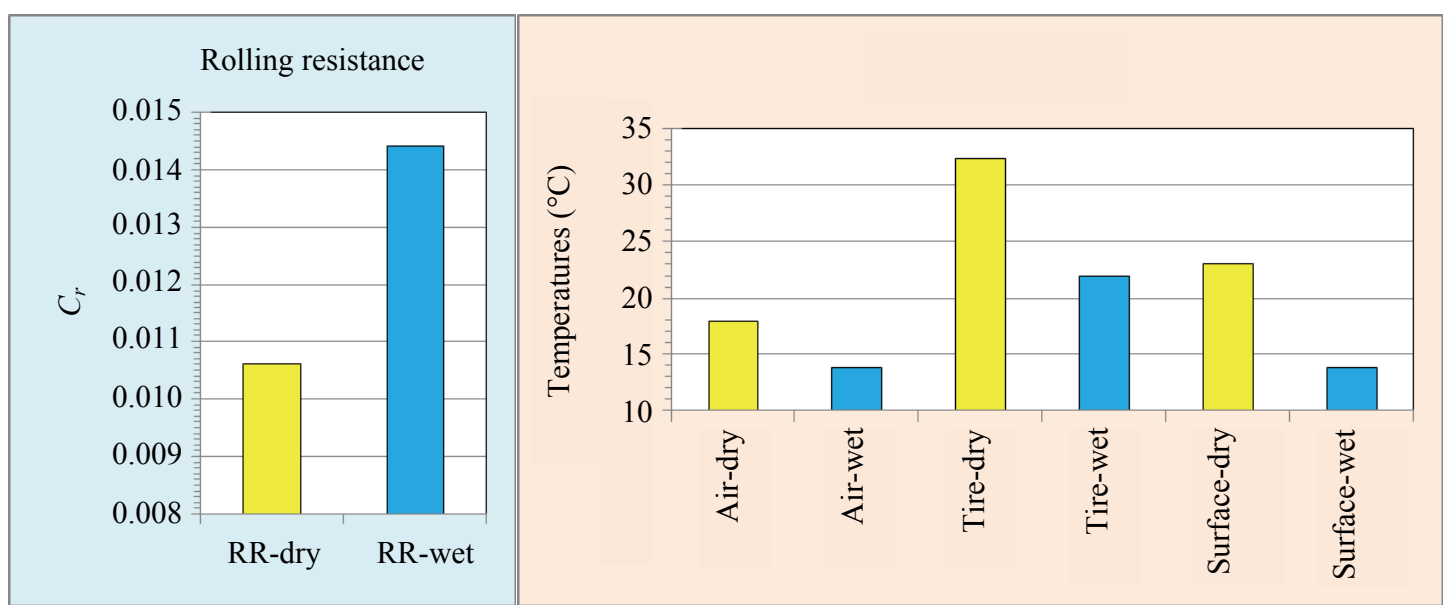

Fig. 15 Influence of wetness on coefficient of rolling resistance and temperatures during measurements for tire MCPRD on SMA8 pavement at speed of $50 \mathrm{~km} / \mathrm{h}$.

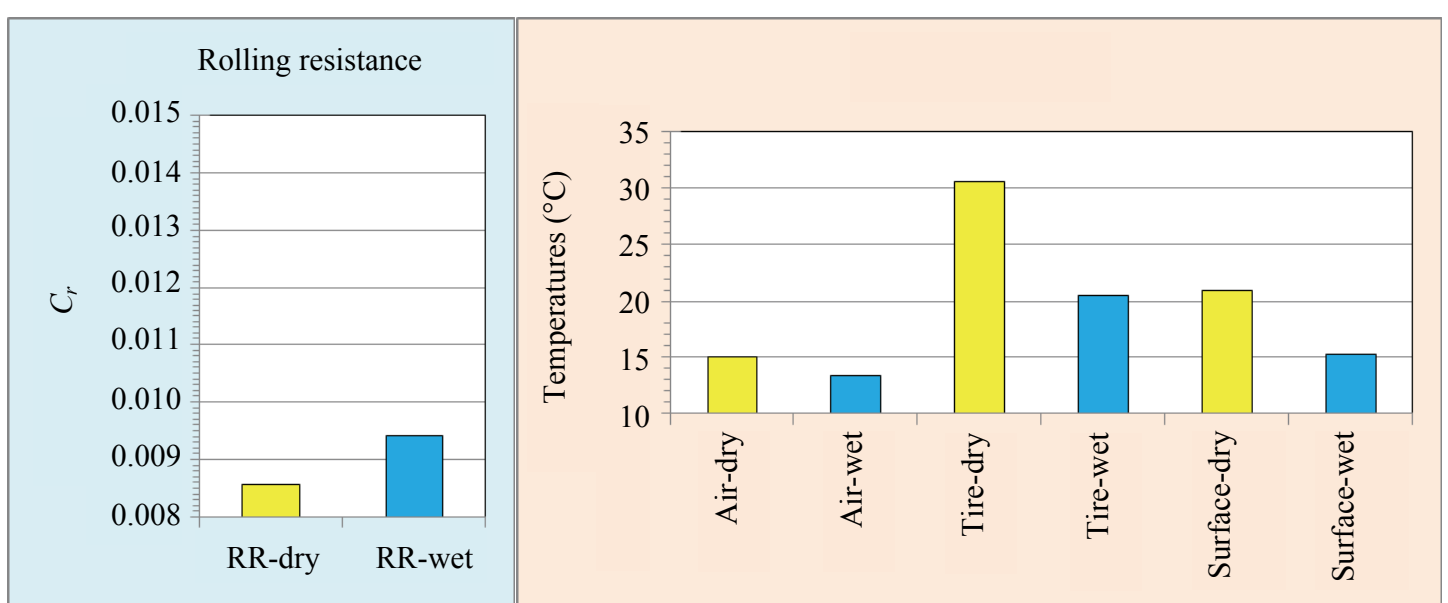

Fig. 16 Influence of wetness on coefficient of rolling resistance and temperatures during measurements for tire SRTTD on SMA8 pavement at speed of $50 \mathrm{~km} / \mathrm{h}$.

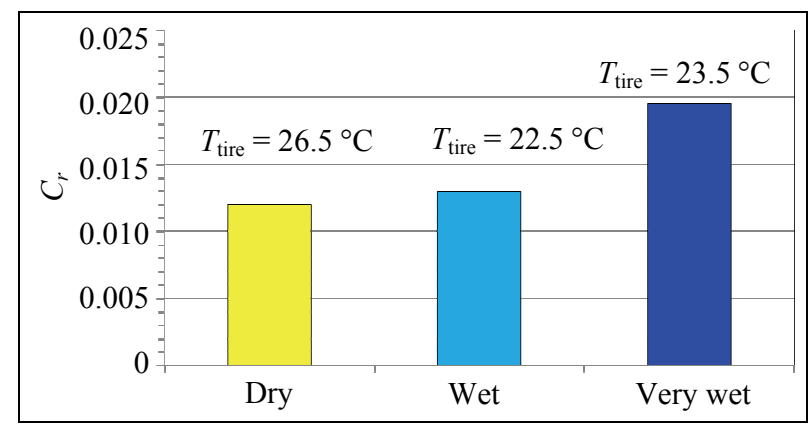

Fig. 17 Influence of wetness on coefficient of rolling resistance and temperatures during measurements for tire VTICD on SD25 pavement at speed of $80 \mathrm{~km} / \mathrm{h}$.

Values calculated above explain most of the rolling resistance increase observed for tires AAV4D and SRTTD. However, rolling resistance increase calculated on the base of temperature change explains only about $25 \%$ of the increase measured for tire
MCPRD. The reason is that this tire was tested during strong rain when water film was deep, while other tires were tested on very thin water film.

Tests performed on road pavement SD25 confirmed findings of other measurements. Tire VTICD was tested in dry, wet and very-wet conditions. The results (rolling resistance coefficient and tire temperature) are presented in Fig. 17. Also for this tire, most of the rolling resistance increase at damp conditions may be explained by cooling effect of wet road surface. For very wet pavement, drop of tire temperature cannot explain all of the rolling resistance increase, thus this additional increase must be caused by hydrodynamic phenomena related to displacement of the water particles at the tire/road interface. 


\section{Conclusions}

Wetness of the road surface increases tire rolling resistance considerably. For certain tires and road surfaces in heavy rain, the increase may be as high as $50 \%$. Generally, it was observed that:

- The increase of rolling resistance is higher for higher speeds;

- Water film thickness has a considerable influence on rolling resistance increase;

- At low speeds $(30 \mathrm{~km} / \mathrm{h})$, even very thin water film has considerable impact on rolling resistance. For higher water film thickness, $C_{r}$ does not increase very much;

- At higher speeds $(50 \mathrm{~km} / \mathrm{h}$ and $80 \mathrm{~km} / \mathrm{h})$, water film thickness has more abrupt influence on rolling resistance. It was especially observed for AAV4D tire which has different tread pattern comparing with SRTT tire. While the thread of AAV4D tire is deeper, the number and density of grooves in the thread pattern is higher for SRTT tires, which allows better accumulation and removal of water;

- The results show that water presented on the road surface cools rolling tires. As tire rolling resistance increases with decrease of its temperature, even very thin water film (less than $0.1 \mathrm{~mm}$ ) that cools the tire has considerable effects on $C_{r}$. In atmospheric conditions existing during the measurements, tire temperature drop of $6 \sim 7{ }^{\circ} \mathrm{C}$ due to surface wetness was observed and this directly increases rolling resistance by about $10 \%$;

- For water films thicker than $0.1 \mathrm{~mm}$, the increase of rolling resistance cannot be explained by temperature drop alone. It is, however, certain that thicker water film must prompt hydrodynamic effects that dissipate energy by water turbulences and create standing "bow" wave at the leading edge of the tire/road footprint. The water wedge on this edge moves the vertical reaction force forward the axel line thus increases rolling resistance;

- Aggregate size in the dense road surfaces has also a considerable influence on the water film thickness resulting in different rolling resistance. It is observed that surfaces with larger aggregate size (SD25) can drain water from surface more easily, resulting in lower rolling resistance increase during very-wet conditions.

Although the test program reported in this article did not covered drainage (porous) type of road surfaces that are more and more often used in certain countries, it is anticipated that, on such surfaces, the rolling resistance increase due to road wetness would be smaller than in the case of dense surfaces. Drainage pavements remove water from the road surface very efficiently, thus in most cases, the water film on the surface is very thin. For such pavements, the rolling resistance increase will be related mostly to the cooling effect of the water, not to the hydrodynamic effects, even during heavy rain. Also rolling resistance on innovative PERS (poroelastic road surfaces) should be less influenced by wetness than on dense pavements.

Good drainage of road surfaces (external or internal) increases road safety by assuring good grip and preventing visibility problems due to excessive splash and spray. On top of this, it may lead to certain economical effects, as it may prevent excessive increase of rolling resistance. According to calculations performed by the authors [6], typically $15 \sim 20 \%$ change of rolling resistance for low and medium speed uninterrupted traffic leads to $5 \sim 8 \%$ change of energy consumption and $\mathrm{CO}_{2}$, as well as toxic gasses emission.

\section{Acknowledgments}

The research work presented in this article is partly sponsored by the European Commission DG RTD and NCBiR (Polish National Centre for Research and Development) within 7th FP "ROSANNE" (Grant Agreement 605368), the Swedish Transport Administration (MIRIAM II) and partly by the NCBiR within national PBS (Applied Research Programme) Project RolRes (Grant No. 
PBS1/A6/1/2012).

\section{References}

[1] Karlsson, R., Carlson, A., and Dolk, E. 2012. Energy Use Generated by Traffic and Pavement Maintenance. VTI Notat 36A-2012.

[2] Swedish Transport Administration. 2015. "MIRIAM Project: Models for Rolling Resistance in Road Infrastructure Asset Management Systems." Swedish Transport Administration. Accessed November 5, 2015. http://www.miriam-co2.net/.

[3] Ejsmont, J., Taryma, S., Ronowski, G., and Świeczko-Żurek, B. 2015. "Parameters Influencing Rolling Resistance and Possible Correction Procedures." Deliverable D3.3. Presented at 7th EU Framework Programme ROSANNE, Brussels, Belgium.
[4] Ejsmont, J., and Świeczko-Żurek, B. 2014. "Methods of Tire Rolling Resistance Measurements." Presented at COTUME (Troisième Congrès Tunisien de Mécanique), Sousse, Tunisia.

[5] Swieczko-Zurek, B., Jaskula, P., Ejsmont, J., Kedzierska, A., and Czajkowski, P. 2015. "Rolling Resistance and Tire/Road Noise on Rubberized Asphalt Pavement in Poland." Presented at Conference Rubberized Asphalt Rubber, Las Vegas, USA.

[6] Ejsmont, J., Świeczko-Żurek, B., and Ronowski, G. 2014. "Rolling Resistance of Tires (Opór toczenia opon samochodowych)." Magazyn Autostrady 7: 38-42.

[7] Morgan, P., Sandberg, U., and Van Blokland, G. 2009. "The Selection of New Reference Test Tyres for Use with the CPX Method: To Be Specified in ISO/TS 11819-3." Presented at INTER-NOISE, Ottawa, Canada. 